\title{
Evaluation of Sweet Potato Leaves and Cassava Leaves Inclusions into the Diet Containing Lemuru Oil on Lipid Metabolism in Local Duck
}

\author{
U. Nurrofingah, Sumiati*, \& Y. Retnani \\ Department of Nutrition and Feed Technology, Faculty of Animal Science, IPB University \\ (Bogor Agricultural University) \\ Jalan Agatis Kampus IPB Dramaga, Bogor 16680, Indonesia \\ *Corresponding author: y_sumiati@yahoo.com \\ (Received 04-09-2019; Revised 20-03-2020; Accepted 23-03-2020)
}

\begin{abstract}
The objective of this study was to evaluate the effects of sweet-potato leaves and cassava leaves inclusions into the diet containing lemuru oil on lipid metabolism of local laying ducks. One hundred and eighty laying ducks with an average body weight of $1657 \mathrm{~g}$ were divided into 6 groups of experimental diets with 3 replications and 10 ducks in each replication. The experiment was arranged in a $2 \times 3$ factorial design. The first factor was the level of sweet potato leaves consisted of 2 levels, i.e., $0 \%$ and $5 \%$. The second factor was the level of cassava leaves consisted of 3 levels, i.e., $0 \%, 5 \%$, and $10 \%$. The variables observed were performance of laying duck, blood, meat, and egg lipid profile, as well as the relationship between the average consumption of $\beta$-carotene with cholesterol concentration in the blood, egg, and meat of laying duck. The results showed that there was no interaction and no effect between sweet potato leaf meal (SPLM) and cassava leaf meal (CLM) on feed consumption. Different levels of SPLM and CLM gave a significant interaction effect $(\mathrm{p}<0.05)$ on body weight gain, with the best interaction, was 5\% SPLM combined with $0 \%$ CLM $(26.60 \mathrm{~g} / \mathrm{duck})$. There was also a significant interaction effect between the combination of $5 \%$ SPLM and $10 \%$ CLM $(p<0.05)$ for reducing the cholesterol, triglyceride, and LDL concentrations in the blood, meat, and egg. Different levels of SPLM and CLM gave significant interaction effects $(p<0.05)$ on the fat contents of flash in laying duck. The fat content of the liver was significantly decreased by $5 \%$ treatment of SPLM $(p<0.05)$. Meat fat decreased significantly with a combination of $5 \%$ SPLM and $10 \%$ CLM $(\mathrm{p}<0.05)$. Treatments with $5 \%$ SPLM or $10 \%$ CLM reduced blood MDA ( $<0.05$ ), while treatments with $10 \%$ CLM reduced the MDA in the liver $(p<0.05)$. It can be concluded that the combination of $5 \%$ SPLM and $10 \%$ CLM in the diets was effective as a source of antioxidants to protect unsaturated fatty acids in the blood, meat, and egg of ducks based on the reduced concentrations of cholesterol, triglyceride, and LDL.
\end{abstract}

Keywords: cassava leaves; cholesterol; duck; sweet potato leaves

\section{INTRODUCTION}

The meat and eggs of ducks are increasingly important culinary items in Indonesia. Therefore, the population of ducks in Indonesia has been expanding and reached 60 million in 2018 (BPS, 2018). West Java is the area with the highest duck population of 12 million in 2018 (BPS, 2018). Duck egg contains $12.00 \mathrm{~g}$ of protein and $14 \mathrm{~g}$ of total fat per $100 \mathrm{~g}$ (USDA, 2018).

Cholesterol is one of the lipid components in the duck egg and meat. Cholesterol levels in duck egg are about $884 \mathrm{mg} / 100 \mathrm{~g}$ egg yolk (USDA, 2018). Cholesterol levels of local-duck eggs are high, around $965 \mathrm{mg} / 100 \mathrm{~g}$ egg yolk (Sumiati et al., 2016). Cholesterol has various important roles in cellular function. Cholesterols are required to construct cell membranes, as precursors to synthesize hormone and forming bile acids needed to digest fat, and participates in lipid formation. In addition, cholesterols are major components of the myelin membrane and the brain contains almost a quarter of the total cholesterol in the body (Simons \& Sampaio, 2011; Zhenyi \& William, 2016). The optimal body health condition can be obtained by consuming cholesterol at normal levels. Normal cholesterol consumption for an adult is $300 \mathrm{mg} /$ day (USDA, 2010). High cholesterol concentrations in the blood will cause precipitations in the wall of blood vessels, thereby increasing the risk of heart disease. One of the solutions to reduce cholesterol concentrations in animal products (meat and egg) of duck was the use of dietary sources of unsaturated fatty acids. Lemuru fish oil is a source of unsaturated fatty acids (Sumiati et al., 2016). Lemuru oil derived from canard sardines in Banyuwangi, contains 6.88\% $\alpha$-linolenic acid, 3.66\% eicosapentaenoic acid (EPA), and 3.55\% docosahexaenoic acid (DHA) (Istiqomah et al., 2017). Unsaturated fatty acids are easily oxidized, and diets containing these fatty acids need to be supplemented with antioxidants as protectors (Arini et al., 2017).

Antioxidants are also known as reductants, compounds that can inhibit oxidation reactions by binding 
to free radicals and highly reactive molecules, thus inhibiting the cell damages (Shahidi \& Zhong, 2015; Winarsi, 2007). One of the ingredients that can be used to protect omega-3 fatty acids from the oxidation process is the use of sweet potato leaf meal (SPLM) and cassava leaf meal (CLM) containing $\beta$-carotene. $\beta$-carotene is an antioxidant that has the potential to protect omega-3 fatty acids (Sumiati et al., 2016).

Sweet potato leaves and cassava leaves are the abundant local-food sources in Indonesia and are agricultural by-products that are largely untapped by humans. Cassava leaves can be used up to $15 \%$ in duck diet without affecting growth performance and diet conversion ratio (Morgan \& Choct, 2016). The cassava leaves can be used in poultry up to the level of $15 \%$ to substitute the soybean meal used in the diet (Abu et al., 2015). In addition to cassava leaves, sweet potato leaves also have potential that can be used as a source of antioxidants ingredients in poultry diets. Sweet potato leaves contain phytosterols, phenols, and flavonoids, which can increase the ability and capacity to neutralize free radicals ( $\mathrm{Fu}$ et al., 2016). Sweet potato leaves were used in the poultry diet with a maximum level of $5 \%$ (Iqbal et al., 2014).

There is no study carried out to explore the feeding value of sweet potato leaves and cassava leaves in diets containing lemuru fish oil as antioxidants. Therefore, the objective of this study was to evaluate the effects of sweet potato leaves and cassava leaves inclusions into the diet containing lemuru oil on lipid metabolism of local laying ducks.

\section{MATERIALS AND METHODS}

All experimental procedures were approved by the Animal Ethics Committee of IPB University (Bogor Agricultural University) by guidelines for the care and use of animals in the study (Number: 120-2018 IPB).

\section{Processing of Sweet Potato Leaves and Cassava Leaves}

Sweet potato leaves were harvested at 120 days and forage was taken up to the 15th leaf below the tip of the shoot. Harvesting of cassava leaves was done at the age of 120 days by taking the 6th to 15th leaves below the tip of the shoots. Sweet potato leaves and cassava leaves were allowed to wilt in a greenhouse until half-dried, so the color of the leaves was still green and then they were dried again in a forced drought oven at $60{ }^{\circ} \mathrm{C}$ for 24 hours. The dried leaves were then ground to pass through a $2 \mathrm{~mm}$ screen size using a Wiley grinder.

\section{Management of Ducks}

This study used 180 local laying ducks selected at the age of 19 weeks old. The experiment was conducted over 12 weeks, with one week of cage adaptation and another week adaptation to the experimental diet. Eighteen cages, each with the size of $2 \mathrm{~m} \times 2 \mathrm{~m} \times 1 \mathrm{~m}$ were used and each cage contained 10 ducks. The experimental ducks were weighed and recorded before the feeding trial during the first week and the 35th week of the experiment. Feeding was restricted and calculated based on the requirement, i.e., $150 \mathrm{~g} / \mathrm{duck} /$ day and drinking water were provided ad libitum. The treatment diets (Table 1) were given twice a day in the morning $(06: 30 \mathrm{~h})$ and in the afternoon (15:30 h.). Feed consumption was recorded on a weekly basis. At the end of the experiment, one duck from each replicate was selected randomly and slaughtered for blood and tissue sample collections.

\section{Blood and Liver Samplings}

Blood samples were taken through the pectoralis vein in the morning at the end of the study (12th week of feeding trial). Liver samples were taken in the morning after slaughtering in the 12th week. Slaughtering was conducted according to the method of halal procedure under the ethical clearance, scalded, de-feathered, and eviscerated (internal organs were removed). The experimental ducks were starved before slaughtering, and the blood samples were taken around 6 hours. Egg samples were taken in the 10th week of the study in the morning. After the 10th week of the study, egg samples were used for hatching.

\section{Blood Lipid Profiles}

Blood total cholesterol, triglyceride, HDL, and LDL concentrations were measured by the methods of Schettler \& Nüssel (1975). Random blood samples were taken from each treatment and repetition. Enzyme reagents and standard solutions were prepared. Preparations made were: a blank tube filled with 1,000 $\mu \mathrm{L}$ of enzyme reagent, a standard tube filled with 10 $\mu \mathrm{L}$ of standard cholesterol solution, $1,000 \mu \mathrm{L}$ of enzyme reagent, sample tube filled with $10 \mu \mathrm{L}$ of blood plasma, and 1,000 $\mu \mathrm{L}$ of enzyme reagent. The mixture was homogenized with a vortex and incubated at $20^{\circ} \mathrm{C}-25^{\circ} \mathrm{C}$ for 10-20 minutes. The absorbance was read at a wavelength of $500 \mathrm{~nm}$ using a spectrophotometer.

\section{Blood and Liver Malondialdehydes (MDA)}

Analysis of blood plasma MDA content was performed using the method of Thiobarbituric Acid Reactive Substances (TBARS), according to Rice-Evans et al. (1991), with a slight modification. About 1,784 mL of concentrated $\mathrm{HCl}, 12 \mathrm{~g}$ of trichloroacetic acid (TCA), and $0.304 \mathrm{~g}$ of thiobarbituric acid (TBA), were placed in a $100 \mathrm{~mL}$ test-tube to make a mixed solution, and was added $80 \mathrm{~mL}$ of distilled water. The mixture solution at the volume of $1.0 \mathrm{~mL}$ was taken and placed in a tube, then mixed with $100 \mu \mathrm{L}$ blood samples and $5 \mathrm{~g}$ of liver samples that had been extracted. The mixture was heated at $80^{\circ} \mathrm{C}$ for 1 hour, then cooled with running water and centrifuged at 2,500 rpm for 10 minutes. The supernatant was used to measure the absorbance at a wavelength of $532 \mathrm{~nm}$. The results of the absorbance were calculated using a linear equation from the standard solution. 


\section{Liver, Egg, and Meat Fat Concentrations}

The liver, egg, and fat meat concentrations were analyzed using the Soxhlet method (AOAC, 2005). Pumpkin fat was dried in an oven at $105^{\circ} \mathrm{C}$ for 30 minutes, then cooled in a desiccator for 15 minutes. The boiling flask that had been cooled was weighed (A). Liver, egg yolk, or meat sample each at the weight of 5 $\mathrm{g}$ were weighed (S) and put into the filter paper and tied with fat-free wool cotton. The filter paper was put into a paper thimble and extracted using hexane for 3-4 hours at $80^{\circ} \mathrm{C}$, then cooled and weighed (B). The fat contents were calculated using the following formula.

Fat contents $(\%)=[(\mathrm{B}-\mathrm{A}) / \mathrm{S}] \times 100 \%$

where: A was the weight of boiling flask before extraction, B was the weight of boiling flask after extraction, and $\mathrm{S}$ was the weight of liver, egg yolk, or meat sample.

\section{Liver and Egg Lipid Profiles}

Measurements of liver cholesterol and egg cholesterol concentrations were conducted by using enzymatic methods (Roeschlau et al., 1974; Allain et al., 1974). A total of $5 \mathrm{~g}$ of the sample (egg yolk or liver) was extracted. Fifty microliters $(50 \mu \mathrm{L})$ of extracts were taken using a micropipette and placed in a test tube, then it was added with a reagent of $1,000 \mu \mathrm{L}$ cholesterol and incubated for 10 minutes at $37^{\circ} \mathrm{C}$. The standard solution was prepared using a standard at the volume of $50 \mu \mathrm{L}$ supplemented with $1,000 \mu \mathrm{L}$ of the cholesterol reagent or triglyceride reagent and then incubated for 10 minutes at $37^{\circ} \mathrm{C}$. The absorbance values of the incubated extract and standard solution were read using a spectrophotometer with a wavelength of $500 \mathrm{~nm}$. HDL and LDL concentrations of egg and meat were measured by the enzymaticcalorimetry method (Burstein et al., 1970). Yolk samples at the weight of $5 \mathrm{~g}$ were extracted using chloroformmethanol $(2: 1 \mathrm{v} / \mathrm{v})$. The extracted yolks were added with a quarter volume of $\mathrm{NaCl}$ solution. The extracted yolk was added with $1,000 \mu \mathrm{L}$ of the kit solution, mixed until homogeneous, then allowed to stand for 10 minutes at $20^{\circ} \mathrm{C}-25^{\circ} \mathrm{C}$ and centrifuged for 10 minutes with 4,000 rounds per minute. The deposits and liquids were separated. The liquid was allowed to stand at room temperature and was read using a spectrophotometer with a wavelength of $546 \mathrm{~nm}$.

Table 1. Nutrient compositions of experimental diets of laying duck (21-30 weeks)

\begin{tabular}{|c|c|c|c|c|c|c|}
\hline \multirow{2}{*}{ Diet composition (\%) } & \multicolumn{6}{|c|}{ Diet treatments } \\
\hline & SOC0 & S0C5 & S0C10 & S5C0 & S5C5 & $\mathrm{S} 5 \mathrm{C} 10$ \\
\hline Yellow corn & 50 & 48.2 & 46.2 & 49.5 & 47.2 & 45 \\
\hline Rice bran & 7.7 & 6 & 4.5 & 4.7 & 4 & 3.2 \\
\hline Soybean meal & 24 & 22.5 & 21 & 22.5 & 21 & 19 \\
\hline SPLM & 0 & 0 & 0 & 5 & 5 & 5 \\
\hline CLM & 0 & 5 & 10 & 0 & 5 & 10 \\
\hline Fishmeal & 7.5 & 7.5 & 7.5 & 7.5 & 7.5 & 7.5 \\
\hline Lemuru fish oil & 3.5 & 3.5 & 3.5 & 3.5 & 3.5 & 3.5 \\
\hline $\mathrm{CaCO}_{3}$ & 6.5 & 6.5 & 6.5 & 6.5 & 6 & 6 \\
\hline $\mathrm{NaCl}$ & 0.2 & 0.2 & 0.2 & 0.2 & 0.2 & 0.2 \\
\hline Premix ${ }^{a)}$ & 0.5 & 0.5 & 0.5 & 0.5 & 0.5 & 0.5 \\
\hline DL-Methionine & 0.1 & 0.1 & 0.1 & 0.1 & 0.1 & 0.1 \\
\hline Total & 100 & 100 & 100 & 100 & 100 & 100 \\
\hline \multicolumn{7}{|l|}{ Nutrient contents } \\
\hline $\operatorname{ME}\left(\mathrm{kcal} \mathrm{kg}^{-1}\right)^{\mathrm{b})}$ & 2859.55 & 2859.10 & 2855.85 & 2857.80 & 2859.85 & 2850.55 \\
\hline Dry material (\%) & 87.94 & 90.80 & 90.97 & 90.77 & 90.86 & 90.93 \\
\hline Ash (\%) & 12.06 & 9.2 & 9.13 & 9.23 & 9.14 & 9.07 \\
\hline Crude protein $(\%)$ & 18.05 & 18.10 & 18.15 & 18.10 & 18.19 & 18.05 \\
\hline Crude fiber (\%) & 2.97 & 3.56 & 4.17 & 3.44 & 4.14 & 4.72 \\
\hline Crude fat (\%) & 5.09 & 4.99 & 4.79 & 4.87 & 4.79 & 5.10 \\
\hline $\mathrm{Ca}(\%)$ & 3.02 & 3.00 & 3.21 & 3.11 & 3.01 & 3.00 \\
\hline P available (\%) & 0.51 & 0.38 & 0.49 & 0.49 & 0.38 & 0.38 \\
\hline$\beta$-carotene $\left(\mathrm{mg} \mathrm{kg}^{-1}\right)$ & 5.28 & 335.65 & 666.02 & 107.97 & 438.32 & 768.67 \\
\hline
\end{tabular}

Note: Source calculation based on Leeson \& Summers, (2005).

SOC0 = Diet without SPLM and CLM; S0C5= Diet contained 0\% SPLM and 5\% CLM; S0C10= Diet contained 0\% SPLM and 10\% CLM; S5C0= Diet contained 5\% SPLM and 0\% CLM; S5C5= Diet contained 5\% SPLM and 5\% CLM; S5C10= Diet contained 5\% SPLM and 10\% CLM.

SPLM= sweet potato leaf meal and CLM= cassava leaf meal.

a)Premix composition 10 kg-1 : 12,000,000 IU Vitamin A, 2,000,000 IU Vitamin D3, 8,000 IU Vitamin E, 2,000 mg Vitamin K, 2,000 mg Vitamin B1, 5,000 mg Vitamin B2, $500 \mathrm{mg}$ Vitamin B6, 12,000 $\mu \mathrm{g}$ Vitamin B12, 25,000 mg Vitamin C, 6,000 mg Calcium D-pantothenate, 40,000 mg Niacin, 10,000 mg Choline chloride, 30,000 mg Methionine, 30,000 mg Lysine, 120,000 mg Manganese, 20,000 mg Iron, $200 \mathrm{mg}$ Iodine, 100,000 mg Zinc, $200 \mathrm{mg}$ Cobalt, 4,000 mg Copper, 21,000 mg Zinc Bacitracin, 10,000 mg Excipient q.s. Production: PT. Mensana Aneka Satwa.

b) Metabolizable energy was calculated on the basis of formula (Bolton, 1967) as follow: $40.81\{0.87$ [crude protein +2.25 crude fat + nitrogen-free extract $]+25\}$ 


\section{Statistical Analysis}

This research used a $2 \times 3$ completely randomized factorial design with three replicates for each treatment. The first factor was the level of sweet potato leaf meal (SPLM) consisted of $0 \%$ and $5 \%$. The second factor was the level of cassava leaf meal (CLM) consisted of $0 \%, 5 \%$, and $10 \%$. The data obtained were analyzed using twoway ANOVA (SAS ${ }^{\circledR}$ University Edition software). If there were interactions and significance, the analysis was continued with a posthoc test by Duncan's multiple range test according to Steel \& Torrie (1993). After all variables were analyzed, the relationship between the average consumption of $\beta$-carotene with cholesterol concentration in the blood, egg and meet of laying duck, would be identified by using regression according to Steel \& Torrie (1993).

\section{RESULTS}

\section{Performance of Laying Ducks}

Table 2 shows that there was no interaction between SPLM and CLM on feed consumptions and initial body weight. The average feed consumption of duck per day during the maintenance was $149.69 \mathrm{~g}$. There was a significant interaction effect $(p<0.05)$ of the levels of SPLM and CLM on fat consumption. Based on the proximate analysis in Table 1, crude fat contents in the diet were different. Table 2 shows that the consumption of diet fat ranges from 7.16-7.63 g/duck/day. Different levels of SPLM and CLM gave a significant interaction effect $(\mathrm{p}<0.05)$ on body weight gain, with the best interaction, was 5\% SPLM combined with 0\% CLM (26.60 g/ duck).

\section{Profiles of Blood Lipid in Laying Ducks}

There were significant interactions between SPLM and CLM treatments $(\mathrm{p}<0.05)$ on the cholesterol, triglycerides, HDL, and LDL concentrations in the blood. The combination of 5\% SPLM with 10\% CLM decreased cholesterol concentrations compared to the other treatments $(\mathrm{p}<0.05)$, while the combination of $5 \%$ SPLM with $5 \%$ or 10\% CLM significantly decreased triglycerides concentrations in the blood $(\mathrm{p}<0.05)$ (Table 3). Combination of $0 \%$ or $5 \%$ SPLM with $10 \%$ CLM significantly increased HDL concentrations $(\mathrm{p}<0.05)$ compared to the other treatments. At low levels of SPLM, the increased levels

Table 2. Performance of laying duck (21-30 weeks) fed ration containing sweet potato leaves meal and cassava leaves meal

\begin{tabular}{lccccc}
\hline \multirow{2}{*}{ Variables } & \multirow{2}{*}{ SPLM } & \multicolumn{3}{c}{ CLM } \\
\cline { 3 - 6 } & & C0 & C5 & C10 & Average \\
\hline Feed consumption (g/duck/day) & S0 & $149.94 \pm 0.09$ & $149.36 \pm 0.54$ & $149.62 \pm 0.32$ & $149.64 \pm 0.40$ \\
& S5 & $149.82 \pm 0.40$ & $149.87 \pm 0.18$ & $149.54 \pm 0.06$ & $149.74 \pm 0.19$ \\
& Average & $149.88 \pm 0.12$ & $149.61 \pm 0.45$ & $149.58 \pm 0.21$ & $149.69 \pm 0.31$ \\
Fat consumption (g/duck/day) & S0 & $7.63 \pm 0.01^{\mathrm{a}}$ & $7.45 \pm 0.27^{\mathrm{b}}$ & $7.16 \pm 0.01^{\mathrm{d}}$ & \\
& S5 & $7.30 \pm 0.01^{\mathrm{c}}$ & $7.44 \pm 0.01^{\mathrm{b}}$ & $7.62 \pm 0.01^{\mathrm{a}}$ & $1673 \pm 63$ \\
Initial body weight (g/duck) & S0 & $1680 \pm 42$ & $1678 \pm 72$ & $1661 \pm 77$ & $1641 \pm 45$ \\
& S5 & $1647 \pm 49$ & $1635 \pm 45$ & $1641 \pm 43$ & $1657 \pm 54$ \\
Body weight gain (g/duck) & Average & $1664 \pm 45$ & $1656 \pm 58$ & $1651 \pm 60$ & $22.75 \pm 0.85^{\mathrm{ab}}$ \\
& S0 & $20.10 \pm 2.37 \mathrm{~b}$ & $19.49 \pm 2.31^{\mathrm{b}}$ & $23.30 \pm 1.06^{\mathrm{ab}}$ & $19.83 \pm 1.36^{\mathrm{b}}$
\end{tabular}

Note: Means in the same column/row with different superscripts had an interaction and differ significantly ( $<<0.05)$. S0C $=$ Diet without SPLM and CLM; S0C5= Diet containing $0 \%$ SPLM and 5\% CLM; S0C10= Diet containing 0\% SPLM and 10\% CLM; S5C0= Diet containing 5\% SPLM and $0 \%$ CLM; S5C5= Diet containing 5\% SPLM and 5\% CLM; S5C10 = Diet containing 5\% SPLM and 10\% CLM. SPLM= sweet potato leaf meal; CLM= cassava leaf meal.

Table 3. Blood lipid profile of laying duck (30 weeks) fed ration containing sweet potato leaves meal and cassava leaves meal

\begin{tabular}{lcccc}
\hline \multirow{2}{*}{ Variables } & SPLM & \multicolumn{3}{c}{ CLM } \\
\cline { 3 - 5 } & & C0 & C5 & C10 \\
\hline Cholesterol (mg/dL) & S0 & $212.85 \pm 2.87^{\mathrm{a}}$ & $196.16 \pm 4.42^{\mathrm{b}}$ & $177.05 \pm 1.38^{\mathrm{c}}$ \\
Triglycerides (mg/dL) & S5 & $217.48 \pm 6.60^{\mathrm{a}}$ & $182.13 \pm 4.05^{\mathrm{b}}$ & $160.31 \pm 1.79^{\mathrm{d}}$ \\
& S0 & $389.06 \pm 4.78^{\mathrm{a}}$ & $375.19 \pm 4.81^{\mathrm{b}}$ & $359.58 \pm 8.38^{\mathrm{c}}$ \\
HDL (mg/dL) & S5 & $366.43 \pm 2.11^{\mathrm{bc}}$ & $321.81 \pm 6.79^{\mathrm{d}}$ & $329.97 \pm 7.25^{\mathrm{c}}$ \\
& S0 & $21.61 \pm 1.23^{\mathrm{d}}$ & $35.55 \pm 3.35^{\mathrm{b}}$ & $45.46 \pm 1.63^{\mathrm{a}}$ \\
LDL (mg/dL) & S5 & $25.02 \pm 0.53^{\mathrm{cd}}$ & $28.53 \pm 2.63^{\mathrm{c}}$ & $40.96 \pm 2.09^{\mathrm{a}}$ \\
& S0 & $83.89 \pm 3.57^{\mathrm{a}}$ & $75.34 \pm 1.14^{\mathrm{b}}$ & $63.20 \pm 3.27^{\mathrm{c}}$ \\
\hline
\end{tabular}

Note: Means in the same row with different superscripts had an interaction and differ significantly $(\mathrm{p}<0.05)$. S0C $0=$ Diet without SPLM and CLM; S0C $5=$ Diet containing $0 \%$ SPLM and 5\% CLM; S0C10= Diet containing 0\% SPLM and 10\% CLM; S5C0= Diet containing 5\% SPLM and 0\% CLM; S5C5= Diet containing 5\% SPLM and 5\% CLM; S5C10 = Diet containing 5\% SPLM and 10\% CLM. SPLM= sweet potato leaf meal; CLM= cassava leaf meal. 
of CLM significantly decreased blood LDL concentrations $(\mathrm{p}<0.05)$ (Table 3).

\section{Profiles of Lipid in the Flesh of Laying Duck}

The effect of different SPLM and CLM levels gave a significant interaction effect $(p<0.05)$ on the profiles of lipid in the flesh of laying duck. The addition of $5 \%$ SPLM combined with 10\% CLM significantly reduced cholesterol, triglyceride, and LDL concentrations in the flesh of experimental laying ducks $(\mathrm{p}<0.05)$. Addition of $0 \%$ or $5 \%$ SPLM combined with $5 \%$ and $10 \%$ CLM significantly increased blood HDL concentrations $(\mathrm{p}<0.05)$ compared to the control treatment (Table 4).

\section{Profiles of Lipids in the Eggs of Laying Ducks}

Different levels of SPLM and CLM gave significant interaction effects $(p<0.05)$ on the triglyceride and HDL concentrations in the eggs of laying duck. The interaction of 5\% SPLM combined with 10\% CLM decreased triglyceride concentrations in the eggs of laying ducks compared to the other treatments $(\mathrm{p}<0.05)$. Addition of $0 \%$ and 5\% SPLM combined with 10\% CLM significantly increased HDL concentrations in the eggs $(p<0.05)$ com- pared to the use of 0\% SPLM and 5\% CLM. Treatment with the high levels of SPLM significantly decreased $(p<0.05)$ cholesterol and LDL concentrations in the eggs of laying ducks. The mean values of cholesterol and LDL concentrations in the eggs were decreased with the increased percentage of SPLM, regardless of the percentage of CLM. Experimental laying ducks fed ration with 5\% SPLM without CLM showed lower egg cholesterol (136.44 mg/egg) and LDL concentrations (61.86 mg/egg) compared to laying ducks without SPM supplementation. Mean cholesterol and LDL concentrations in the eggs of laying ducks supplemented with 5\% SPLM combined with 0,5 , and 10\% CLM showed a decreased cholesterol (131.06 mg/egg) and LDL (45.66 mg/ egg) concentrations compared to laying ducks without SPM supplementation.

\section{Fat Concentrations in the Liver, Egg, and Flesh of Laying Ducks}

Different levels of SPLM and CLM gave significant interaction effects $(p<0.05)$ on the fat contents of flash in laying duck. Table 6 shows that the supplementation of SPLM at the level of 5\% significantly reduced the concentrations of fat in the livers of experimental ducks

Table 4. Meat lipid profile of laying duck (30 weeks) fed ration containing sweet potato leaves meal and cassava leaves meal

\begin{tabular}{|c|c|c|c|c|}
\hline \multirow{2}{*}{ Variables } & \multirow{2}{*}{ SPLM } & \multicolumn{3}{|c|}{ CLM } \\
\hline & & $\mathrm{C} 0$ & $\mathrm{C} 5$ & $\mathrm{C} 10$ \\
\hline \multirow[t]{2}{*}{ Cholesterol (mg/100g) } & SO & $80.00 \pm 1.00^{a}$ & $73.67 \pm 0.58^{\mathrm{b}}$ & $74.33 \pm 0.58^{\mathrm{b}}$ \\
\hline & S5 & $80.67 \pm 1.15^{\mathrm{a}}$ & $72.67 \pm 0.58^{\mathrm{b}}$ & $68.33 \pm 0.58^{c}$ \\
\hline \multirow[t]{2}{*}{ Triglycerides (mg/100g) } & So & $162.00 \pm 4.00^{\mathrm{a}}$ & $154.67 \pm 1.15^{\mathrm{bc}}$ & $153.00 \pm 2.64^{\mathrm{c}}$ \\
\hline & S5 & $160.67 \pm 2.08^{\mathrm{ab}}$ & $154.67 \pm 3.21^{\mathrm{bc}}$ & $116.67 \pm 1.15^{\mathrm{d}}$ \\
\hline \multirow[t]{2}{*}{ HDL (mg/100g) } & So & $12.33 \pm 0.57^{a}$ & $16.33 \pm 0.57^{b}$ & $17.67 \pm 1.15^{\mathrm{b}}$ \\
\hline & S5 & $17.33 \pm 1.52^{\mathrm{b}}$ & $17.33 \pm 1.52^{\mathrm{b}}$ & $16.33 \pm 0.57^{b}$ \\
\hline \multirow[t]{2}{*}{ LDL (mg/100g) } & So & $41.73 \pm 2.05^{\mathrm{a}}$ & $29.93 \pm 0.98^{\mathrm{b}}$ & $26.40 \pm 1.05^{c}$ \\
\hline & S5 & $26.06 \pm 1.61^{c}$ & $23.8 \pm 0.35^{c}$ & $20.00 \pm 1.15^{\mathrm{cd}}$ \\
\hline
\end{tabular}

Note: Means in the same column/row with different superscripts had an interaction and differ significantly $(\mathrm{p}<0.05)$. SOC $=$ Diet without SPLM and CLM; S0C5= Diet containing 0\% SPLM and 5\% CLM; S0C10= Diet containing 0\% SPLM and 10\% CLM; S5C0= Diet containing 5\% SPLM and 0\% CLM; S5C5= Diet containing 5\% SPLM and 5\% CLM; S5C10 = Diet containing 5\% SPLM and 10\% CLM. SPLM= sweet potato leaf meal; CLM= cassava leaf meal.

Table 5. Egg lipid profiles of laying duck (30 weeks) fed ration containing sweet potato leaves meal and cassava leaves meal

\begin{tabular}{|c|c|c|c|c|c|}
\hline \multirow{2}{*}{ Variables } & \multirow{2}{*}{ SPLM } & \multicolumn{3}{|c|}{ CLM } & \multirow{2}{*}{ Average } \\
\hline & & $\mathrm{CO}$ & $\mathrm{C} 5$ & $\mathrm{C} 10$ & \\
\hline \multirow[t]{3}{*}{ Cholesterol (mg/egg) } & S0 & $158.04 \pm 2.89$ & $169.98 \pm 5.76$ & $136.44 \pm 5.92$ & $154.82 \pm 15.35^{x}$ \\
\hline & S5 & $136.44 \pm 5.92$ & $136.50 \pm \quad 4.77$ & $120.24 \pm 7.56$ & $131.06 \pm 9.72^{y}$ \\
\hline & Average & $147.24 \pm 12.54^{\mathrm{a}}$ & $153.24 \pm 18.93^{a}$ & $128.34 \pm 10.75^{\mathrm{b}}$ & \\
\hline \multirow[t]{2}{*}{ Triglycerides (mg/egg) } & S0 & $2517.12 \pm 11.68^{\mathrm{a}}$ & $2180.82 \pm 19.32^{\mathrm{b}}$ & $2306.16 \pm 9.09^{b}$ & \\
\hline & S5 & $2199.36 \pm 49.14^{\mathrm{b}}$ & $1921.32 \pm 116.09 c$ & $1699.44 \pm 12.62^{\mathrm{d}}$ & \\
\hline \multirow[t]{2}{*}{ HDL (mg/egg) } & S0 & $42.48 \pm 1.47 \mathrm{c}$ & $70.50 \pm 3.53^{\mathrm{b}}$ & $79.08 \pm 2.79^{a}$ & \\
\hline & S5 & $67.08 \pm 2.31^{b}$ & $73.02 \pm 2.08^{b}$ & $84.00 \pm 1.05^{\mathrm{a}}$ & \\
\hline \multirow[t]{3}{*}{ LDL (mg/egg) } & So & $67.74 \pm 4.67$ & $52.02 \pm \quad 3.64$ & $40.26 \pm 2.87$ & $53.34 \pm 12.38^{x}$ \\
\hline & S5 & $61.86 \pm 4.77$ & $40.86 \pm 5.65$ & $34.26 \pm 2.45$ & $45.66 \pm 13.07 \mathrm{y}$ \\
\hline & Average & $64.80 \pm 5.31^{\mathrm{a}}$ & $46.44 \pm 7.44^{\mathrm{b}}$ & $37.26 \pm 4.06^{c}$ & \\
\hline
\end{tabular}

Note: Means in the same column/row with different superscripts had an interaction and differ significantly ( $<<0.05)$. S0C0= Diet without SPLM and CLM; S0C5 = Diet containing 0\% SPLM and 5\% CLM; S0C10= Diet containing 0\% SPLM and 10\% CLM; S5C0= Diet containing 5\% SPLM and 0\% CLM; S5C5= Diet containing 5\% SPLM and 5\% CLM; S5C10 = Diet containing 5\% SPLM and 10\% CLM. SPLM= sweet potato leaf meal; CLM= cassava leaf meal. 
Table 6. Percentages of fat in the liver, egg, and flesh of laying duck (30 weeks) fed ration containing sweet potato leaves meal and cassava leaves meal

\begin{tabular}{|c|c|c|c|c|c|}
\hline \multirow{2}{*}{ Variables } & \multirow{2}{*}{ SPLM } & \multicolumn{3}{|c|}{ CLM } & \multirow{2}{*}{ Average } \\
\hline & & $\mathrm{C} 0$ & $\mathrm{C} 5$ & $\mathrm{C} 10$ & \\
\hline \multirow[t]{3}{*}{ Liverfat (g/duck) } & S0 & $2.25 \pm 0.09$ & $2.64 \pm 0.15$ & $1.78 \pm 0.36$ & $2.22 \pm 0.43^{x}$ \\
\hline & S5 & $1.36 \pm 0.66$ & $1.32 \pm 0.49$ & $1.53 \pm 0.54$ & $1.40 \pm 0.50 y$ \\
\hline & Average & $1.80 \pm 0.64$ & $1.98 \pm 0.79$ & $1.65 \pm 0.43$ & \\
\hline \multirow[t]{3}{*}{ Egg fat (\%) } & So & $29.02 \pm 0.38$ & $29.21 \pm 0.76$ & $29.85 \pm 1.17$ & $29.26 \pm 0.77$ \\
\hline & S5 & $29.67 \pm 0.64$ & $28.85 \pm 1.18$ & $28.85 \pm 1.33$ & $29.45 \pm 1.05$ \\
\hline & Average & $29.39 \pm 0.51$ & $29.53 \pm 0.97$ & $28.35 \pm 1.25$ & $29.35 \pm 1.33$ \\
\hline \multirow[t]{2}{*}{ Flesh fat $(\%)$} & So & $9.78 \pm 0.30^{\mathrm{a}}$ & $7.26 \pm 0.40^{\mathrm{b}}$ & $7.42 \pm 0.43^{b}$ & \\
\hline & S5 & $7.87 \pm 0.80^{\mathrm{b}}$ & $6.18 \pm 0.41^{\mathrm{c}}$ & $4.70 \pm 0.25^{\mathrm{d}}$ & \\
\hline
\end{tabular}

Note: Means in the same column/row with different superscripts had an interaction and differ significantly ( $<0.05)$. S0C $0=$ Diet without SPLM and CLM; S0C5= Diet containing 0\% SPLM and 5\% CLM; S0C10= Diet containing 0\% SPLM and 10\% CLM; S5C0= Diet containing 5\% SPLM and 0\% CLM; S5C5= Diet containing 5\% SPLM and 5\% CLM; S5C10 = Diet containing 5\% SPLM and 10\% CLM. SPLM= sweet potato leaf meal; CLM= cassava leaf meal.

$(\mathrm{p}<0.05)$. However, supplementation of $0 \%$ and $5 \%$ SPLM combined with $0 \%, 5 \%$, and 10\% CLM did not affect the fat contents of eggs produced by the laying duck (Table 6).

\section{Concentrations of MDA in the Blood and Liver of Laying Ducks}

There was no interaction between SPLM and CLM on the the blood and livers of laying ducks. The supplementation of 5\% SPLM markedly reduced blood MDA concentrations in the experimental ducks $(\mathrm{p}<0.05)$. Based on Table 7 , the supplementation of $10 \%$ CLM significantly decreased MDA concentrations in the blood and livers of experimental ducks $(\mathrm{p}<0.05)$.

The highest consumption of $\beta$-carotene was found in ducks fed a diet containing lemuru fish oil supplemented with 5\% SPLM combined with 10\% CLM. Regression test of $\beta$-carotene consumption with blood cholesterol concentrations of experimental ducks showed a negative linear regression with the equation of the line $Y=-4.7185 x+218.39$ with the coefficient of determination $(\mathrm{R} 2)=0.9348$ (Figure 1$)$. Regression test of $\beta$-carotene consumption on meat cholesterol concentrations of experimental ducks showed a linear negative response with the equation of the line $Y=-0.9243 x+$ 80.31 with the coefficient of determination $(\mathrm{R} 2)=0.7962$ (Figure 1). Regression test of $\beta$-carotene consumption with duck egg cholesterol level shows a linear negative response with the equation of the line $Y=-5.3577 x$ +518 with the coefficient of determination $(\mathrm{R} 2)=0.1593$ (Figure 1).

\section{DISCUSSION}

There was no significant effect of SPLM and CLM on feed consumptions of laying ducks. According to Leeson \& Summers (2005), feed consumption is affected by species, humidity, egg mass index, and energy in the diet. The consumption of different dietary fats was due to the different diet compositions with consideration of iso protein and iso energy. Consumption of dietary fat is still within the normal limits. According to Leeson \& Summers (2005), the maximum limit of fat composition in the diet is $7 \%$ or $10.5 \mathrm{~g} /$ duck/day in laying ducks. Consuming excess fat or less in laying poultry could cause reproductive problems that eventually decreased egg production. This condition is caused by unstable reproductive hormone conditions. One of the fat components, which is a precursor of reproductive hormones, is cholesterol (Zhenyi \& William, 2016). There was a significant interaction effect of SPLM and CLM on body weight gain. The body weight gain in this study was lower than those observed by other researchers who work on meat ducks.

Table 7. Blood MDA and liver MDA concentrations in laying duck (30 weeks) fed ration containing sweet potato leaves meal and cassava leaves meal

\begin{tabular}{|c|c|c|c|c|c|}
\hline \multirow{2}{*}{ Variables } & \multirow{2}{*}{ SPLM } & \multicolumn{3}{|c|}{ CLM } & \multirow{2}{*}{ Average } \\
\hline & & $\mathrm{CO}$ & $\mathrm{C} 5$ & C10 & \\
\hline \multirow[t]{3}{*}{ Blood MDA (nmol/mL) } & SO & $4.61 \pm 0.15$ & $4.21 \pm 0.18$ & $3.27 \pm 0.30$ & $4.03 \pm 0.62^{x}$ \\
\hline & S5 & $3.94 \pm 0.71$ & $3.20 \pm 0.01$ & $2.84 \pm 0.05$ & $3.33 \pm 0.60 y$ \\
\hline & Average & $4.28 \pm 0.59^{a}$ & $3.71 \pm 0.56^{\mathrm{a}}$ & $3.06 \pm 0.30^{\mathrm{b}}$ & \\
\hline \multirow[t]{3}{*}{ Liver MDA (nmol/mg) } & SO & $2.08 \pm 0.38$ & $1.59 \pm 0.37$ & $0.90 \pm 0.14$ & $1.52 \pm 0.58$ \\
\hline & S5 & $1.50 \pm 0.20$ & $0.87 \pm 0.12$ & $0.73 \pm 0.34$ & $0.90 \pm 0.54$ \\
\hline & Average & $1.79 \pm 0.42^{\mathrm{a}}$ & $1.23 \pm 0.46^{\mathrm{b}}$ & $0.81 \pm 0.38^{c}$ & \\
\hline
\end{tabular}

Note: Means in the same column/row with different superscripts had an interaction and differ significantly (p<0.05). S0C0= Diet without SPLM and CLM; S0C5= Diet containing 0\% SPLM and 5\% CLM; S0C10= Diet containing 0\% SPLM and 10\% CLM; S5C0= Diet containing 5\% SPLM and 0\% CLM; S5C5= Diet containing 5\% SPLM and 5\% CLM; S5C10 = Diet containing 5\% SPLM and 10\% CLM. SPLM= sweet potato leaf meal; CLM= cassava leaf meal. 


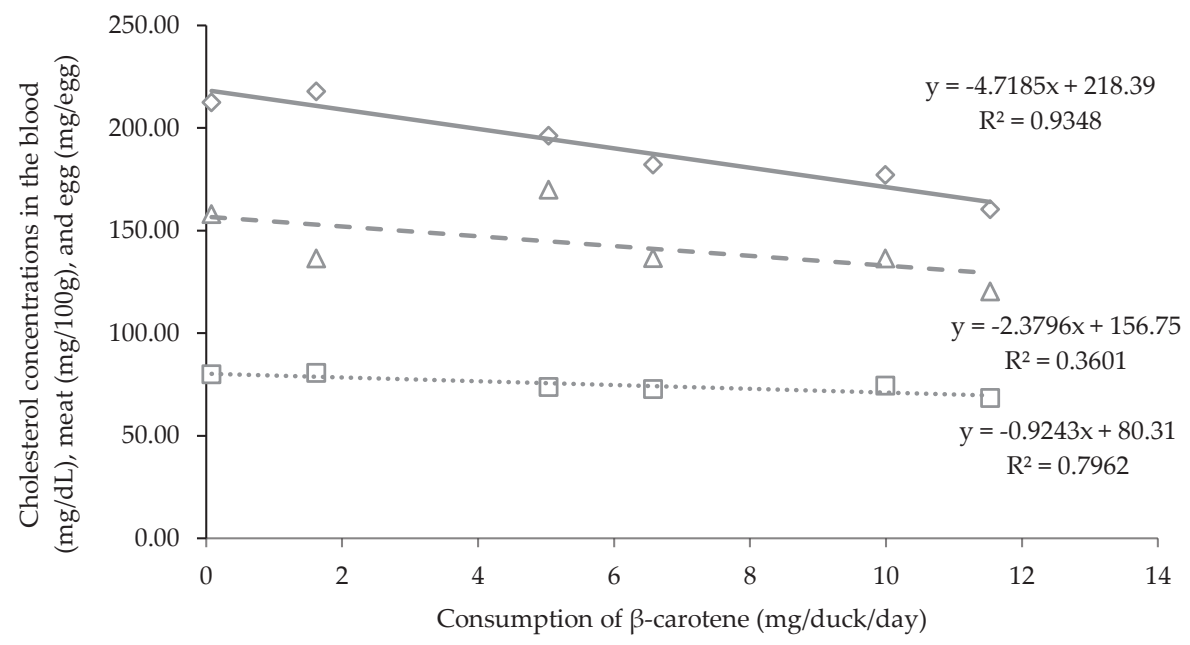

Figure 1. The relationship between the average consumption of $\beta$-carotene with cholesterol concentrations in the blood $(-\diamond-)$, egg $(-\Delta-)$, and meat (-口-) of laying duck.

There was a significant interaction $(p<0.05)$ effect of SPLM and cassava leaf meal on the blood cholesterol, triglycerides, HDL, and LDL concentrations. The antioxidant activity will prevent and inhibit the process of lipid peroxidation in the plasma so that it causes the reduction of plasma cholesterol concentrations (Laudadio et al., 2014).

The decreased blood triglyceride concentrations were caused by the $\beta$-carotene content found in SPLM and CLM. $\beta$-carotene was a potential natural antioxidant that would prey on free radicals so that the activity of the lipoprotein lipase enzyme would increase (Schreiber et al., 2013). Lipoprotein lipase was activated by Apolipoprotein $\mathrm{C}$ and functions in hydrolyzing triglycerides to fatty acids and glycerol that eventually decreased blood triglycerides concentrations (Schreiber et al., 2013).

Antioxidants in the form of $\beta$-carotene found in sweet potato leaves and cassava leaves also function to protect omega- 3 fatty acids that are present in the lemuru fish oil. Unsaturated long-chain fatty acids in the form of omega-3 found in lemuru fish oil are EPA $(9.41 \%)$ and DHA $(9.76 \%)$, which are easily oxidized (Hulu et al., 2017). Omega-3 fatty acids found in Lemuru fish oil reduce the availability of fatty acids for triglyceride synthesis by inhibiting the activity of Phosphatidic Acid Phosphohydrolase (PAP) and the Diacyl Glycerol Transferase (DGAT) enzymes. The inhibition of triglycerides synthesis causes a decrease in the production of triglycerides in the plasma. The endogenous lipid metabolism controls the accumulation of triglycerides in the liver.

Blood HDL concentrations would increase due to the synergy of SPLM and CLM at the optimal levels. $\beta$-carotene found in SPLM and CLM causes an increase in the incorporation of cholesterol esterification in HDL-C, which is then transported to the liver (CarvajalZarrabal et al., 2005). Cholesterol found in the liver was then converted to chenochocolic acid and cholic acid; both types of acid are then secreted into the bile and converted to bile acids. Bile acids are then stored in the gallbladder and secreted into the small intestine to help digest the fat in the diet. This condition will decrease the total blood cholesterol concentration and then increases the plasma HDL concentrations.

There was a significant interaction effect of SPLM and CLM on the concentrations of cholesterol in the duck meat. $\beta$-carotene in SPLM and CLM functions as an antioxidant, which causes the increased secretion of bile acids. $\beta$-carotene is an important bioactive component as a precursor of vitamin A and retinoids, which describes important molecules in animal nutrition (Meng et al., 2019; Green \& Fascetti, 2016). High concentrations of $\beta$-carotene can increase oxidative stability and provide a safe source of $\beta$-carotene for nutrition and human health (Laudadio et al., 2014). The use of SPLM and CLM containing $\beta$-carotene as an antioxidant in the diet has the potential to limit the formation of lipid oxidation products, especially in omega-3-enriched meats.

There was a significant interaction effect of SPLM and CLM on triglycerides concentrations in the duck meat. Neutral triglycerides are the fat with the biggest proportion in food and are used as energy reserves stored in adipose and muscle tissue (McKee \& McKee, 2013). The decreased levels of triglycerides in duck meat caused by the activity of the hormone-sensitive lipase (HSL). HSL plays a role in catalyzing the breakdown of triglyceride deposits into free fatty acids and glycerol, then the free fatty acids that are released into the circulation bind to albumin (Schweiger et al., 2014).

Low levels of cholesterol, triglycerides, and LDL in the ducks fed ration with 5\% SPLM combined with $10 \%$ CLM are related to anthocyanin contents of sweet potato leaves which function as antioxidants to reduce cholesterol synthesis. The LDL mass consists of $50 \%$ cholesterol (Liu et al., 2010). The level of $\beta$-carotene in CLM has the potential to be an antioxidant (McNulty et al., 2008). The presence of antioxidant activity can inhibit and prevent lipid peroxidation in plasma, which would affect the reduction of cholesterol in LDL (Laudadio et al., 2014).

There was a significant interaction effect of SPLM and CLM on the contents of cholesterol in the eggs. Cholesterol reduction is probably caused by $\beta$-carotene, 
which is a good natural antioxidant (Schreiber et al., 2013) and functions to increase oxidative stability by suppressing the occurrence of lipid peroxidation (Laudadio et al., 2014). Lipid oxidation can be caused by various factors, including temperature, $\mathrm{pH}$, exposure to UV light, and the ratio of antioxidants and pro-oxidants (Trujillo et al., 2016). The content of $\beta$-carotene in CLM in diet would affect the high antioxidant content in the egg. Antioxidants function to reduce free radicals. According to Surai et al. (2016), antioxidants in lipids would survive in the presence of carotenoids.

There was a significant interaction effect of SPLM and CLM on the reduction of triglycerides in the duck egg. Triglycerides are monomers of lipids consisting of three fatty acid molecules and one glycerol molecule. The results of the addition of CLM were the reduction of triglyceride concentrations due to the presence of carotenoids in CLM. Lemuru fish oil has a double bond so that it is easily oxidized (Shahidi \& Zhong, 2010). Carotenoids would maximize the work of Lemuru fish oil because it is not easily oxidized. Omega- 3 fatty acids have two ways to reduce cholesterol by stimulating cholesterol excretion from the liver to the intestine through bile and increasing cholesterol catabolism to the liver carried by HDL and converted into bile acids so that regeneration does not occur but is excreted by excretion system. Omega-3 fatty acids contain EPA and DHA, which can reduce cholesterol content, where cholesterol is a by-product of fatty acid hydrolysis. According to Levi et al. (2009), cholesterol is a precursor of steroid hormones. The estrogen will stimulate the synthesis of vitellogenin membrane. Vitellogenin is a precursor for egg yolk synthesis. Vitellogenin is rich in lipids, protein, and cholesterol. Changes in the need for cholesterol to produce vitellogenin would affect the cholesterol concentrations found in blood, meat, liver, and egg.

There was a significant effect of SPLM on reducing LDL concentrations in the eggs of experimental duck. This effect is related to the isoflavone contents of sweet potato leaves, having the potential to inhibit the absorption of cholesterol that eventually decreases and inhibits the formation of VLDL and decreases LDL concentrations. Isoflavones are flavonoids that function as antioxidants, antimicrobials, anticancer agents, and anti-inflammatory (Yu et al., 2016). Plant sterols (phytosterols) can inhibit the absorption of cholesterol. Phytosterols will compete and replace the position of cholesterol in the micelle so that the absorption of cholesterol by the intestine is reduced as a result of the inhibition of chylomicron and VLDL formations that eventually decrease LDL. LDL in egg yolk is also synthesized in the liver, which is derived from the hydrolysis of IDL (intermediate density lipoprotein) by the enzyme lipoprotein lipase to produce LDL that will be secreted into the blood circulation and transported into the oocytes in the ovaries. The decreased LDL concentrations in the eggs in this experiment was related to the isoflavone contents of sweet potato leaves that can inhibit the absorption of cholesterol that eventually inhibited the formation of VLDL and reduces LDL concentrations.
The normal consumption of cholesterol for adults is $300 \mathrm{mg} /$ day (USDA, 2010). Based on Table 7, it is known that the use of 5\% SPLM combined with 10\% CLM in lemuru fish oil diet is the best treatment for the reduction of cholesterol concentration in the egg to $120.24 \mathrm{mg} /$ duck egg. The reduction of cholesterol contents of the duck eggs indicates that eggs produced by ducks fed diet containing lemuru fish oil with 5\% SPLM and 10\% CLM as a source of antioxidants, can be consumed up to two and half eggs per day.

There was a significant effect of SPLM on liver fat. The high-fat content is influenced by the composition of the diet, especially the energy content of the diet, the ratio of protein-energy, and fat contents of the diet (Maryuni \& Wibowo, 2005). According to Choi et al. (2010), fat plays an important role in the stability of meat emulsions increased water capacity, and the level of meat hardness. Decreased levels of meat fat would improve the health status of these meat products. Increased levels of meat fat are influenced by the age of livestock, diet, and animal genetic makeup (Baeza, 2006). High levels of fat in duck meat would increase consumer appeal (Baeza, 2006). According to Cao et al. (2018), lipid synthesis in laying ducks (cholesterol and triglycerides) is mostly occurred in the liver and then transported by lipoproteins to the ovarian follicles and involved in egg-yolk production. According to Scorletti \& Byrne (2013), the process of synthesis of uncontested fat causes the accumulation in the liver and can be toxic.

There was a significant interaction effect of SPLM and CLM on the fat content of duck meat. It can be concluded that the provision of unsaturated fatty acids in the form of omega-3 will work optimally with the addition of antioxidant sources.

There was no significant effect of SPLM and CLM on the fat concentrations of duck eggs. This nonsignificant effect can be caused by the fact that the formation of the concentric yolk layer is more influenced by xanthophyll in the diet and pituitary hormones. Duck egg yolk is the product of follicular development. The development of follicles in the ovary is controlled by the presence of FSH and deposition of vitellogenin into the developing follicles. Antioxidants and lemuru oil in sweet potato leaves meal and CLM can increase the production of vitellogenin by the liver cells. The decreased vitellogenin production due to the accelerated liver cell degeneration causes the same percentage of egg fat in each treatment (Watson, 2002). The same percentage of egg fat can also be caused by the content of SPLM and CLM in the diet, which is not yet optimal so that it does not affect the duck egg.

There was a significant effect of SPLM on blood MDA. It concluded that sweet potato leaves have a function as an antioxidant. The antioxidant activity of sweet potato leaves has a FRAP value of $70 \mu \mathrm{MTE} / \mathrm{g}$ that is higher than that of cassava leaves, which has a FRAP value of $40 \mu \mathrm{MTE} / \mathrm{g}$. A high FRAP value indicates that SPLM can reduce $\mathrm{Fe}^{3+}$ to $\mathrm{Fe}^{2+}$. $\mathrm{Fe}^{2+}$ is important in the process of channeling and increasing oxygen in the blood. The blood containing $\mathrm{Fe}^{3+}$ is called methemoglobin and only tolerates a maximum of $2 \%$ of the total hemoglobin in the blood, if the $\mathrm{Fe}^{3+}$ level is more than $2 \%$, 
it will disturb the efficiencies of oxygens distributions throughout the body. This indicates that SPLM has the potential to be used as an anti-stress.

There was a significant effect of CLM on liver MDA. Cassava leaf meal has a function as an antioxidant. The antioxidant activity of CLM, having an $\mathrm{IC}_{50}$ value of $373.10 \mu \mathrm{g} / \mathrm{mL}$ is higher than that of sweet potato leaves having an $\mathrm{IC}_{50}$ value of $592.31 \mu \mathrm{g} / \mathrm{mL}$. DPPH is a stable free radical that, when reacted with antioxidants, would change color from purple to yellow. DPPH measures antioxidants in general, not based on the type of free radicals that are inhibited. $\mathrm{IC}_{50}$ values interpret that with a concentration of $373.10 \mu \mathrm{g} / \mathrm{mL}$, cassava leaves can reduce $50 \%$ DPPH activity while using sweet potato leaves, the concentration required to reduced $50 \% \mathrm{DPPH}$ is $592.31 \mu \mathrm{g} / \mathrm{mL}$

The highest consumption of $\beta$-carotene was found in ducks fed a diet containing lemuru fish oil supplemented with 5\% SPLM combined with 10\% CLM. Correlation test of $\beta$-carotene consumption with blood cholesterol concentrations of experimental ducks showed a negative linear correlation with the equation of the line $Y=-4.7185 x+218.39$ with the coefficient of determination $\left(R^{2}\right)=0.9348$ (Figure 1). It can be concluded that the higher levels of $\beta$-carotene in the diet would be positively correlated with the reduction in blood cholesterol concentrations in 30-week-old laying ducks. Correlation test of $\beta$-carotene consumption on meat cholesterol concentrations of experimental ducks showed a linear negative response with the equation of the line $Y=-0.9243 x+80.31$ with the coefficient of determination $\left(R^{2}\right)=0.7962$ (Figure 1). It can be concluded that the higher levels of $\beta$-carotene in the diet would greatly reduce cholesterol concentrations in 30-week-old laying duck. Correlation test of $\beta$-carotene consumption with duck egg cholesterol level shows a linear negative response with the equation of the line $Y=-5.3577 x+518$ with the coefficient of determination $\left(R^{2}\right)=0.1593$ (Figure 1). It can be concluded that the higher the levels of $\beta$-carotene in the diet would greatly reduce cholesterol concentrations in the eggs produced by 30-weeks-old laying duck. $\beta$-carotene contained in sweet potato leaves and cassava leaves can reduce concentrations of cholesterol in the blood, meat, and egg. The interaction effect of 5\% SPLM combined with $10 \%$ CLM supplementation in the diet containing lemuru fish oil increases the consumption of $\beta$-carotene in laying ducks and provides a positive response to the reduction of concentrations of cholesterol in the blood, meat, and eggs of experimental ducks. When it first enters the body and is carried by the blood to the liver and the other body tissues, the effect of $\beta$-carotene on the reduction of cholesterol is very visible. However, when $\beta$-carotene is metabolized in the meat, the antioxidant effect in reducing cholesterol decreases, and when the $\beta$-carotene enters the product (egg) the antioxidant effects in reducing cholesterol decreased in a greater level. These phenomena indicate that although the addition of antioxidant sources and lemuru fish oil is quite high, the experimental laying ducks will still maintain the nutrient content, especially fat (cholesterol) in the eggs to support the growth and development of embryos in the eggs. The laying duck will choose to reduce the cholesterol content in the body to be transported to the egg, so it is very difficult to reduce the cholesterol concentrations in the eggs by more than $25 \%$.

\section{CONCLUSION}

The combination of $5 \%$ sweet potato leaf meal and $10 \%$ cassava leaf meal into a diet containing lemuru oil was effective as a source of antioxidants to protect unsaturated fatty acid based on the reduced concentrations of cholesterol, triglyceride, and LDL in the blood, meat, and eggs of experimental laying ducks.

\section{CONFLICT OF INTEREST}

We certify that there is no conflict of interest with any financial, personal, or other relationships with the other people or organizations related to the material discussed in the manuscript.

\section{ACKNOWLEDGEMENT}

This research was financially supported by Director General of Strengthening Research and Development, Ministry of Research Technology and Higher Education of the Republic of Indonesia with IPB University, Number: 129/SP2H/PTNBH /DRPM/2018 dated February, $1^{\text {th }} 2018$.

\section{REFERENCES}

Abu, O. A., I. F. Olaleru, \& A. B. Omojola. 2015. Carcass characteristics and meat quality of broilers fed cassava peel and leaf meals as replacements for maize and soyabean meal. J. Agric. Vet. Sci. 8:41-46.

Allain, C. C., S. P. Lucy, S. G. C. Cicely, W. Richmond, \& C. F. Paul. 1974. Enzymatic determination of total serum cholesterol. Clin. Chem. 20:470-475. https://doi.org/10.1093/ clinchem/20.4.470

AOAC. 2005. Official Methods of Analysis of AOAC International. 18th ed. Assoc. Off. Anal. Chem., Arlington.

Arini, N. M. J., Sumiati, \& R. Mutia. 2017. Evaluation of feeding Indigofera zollingeriana leaf meal and Sardinella lemuru fish oil on lipids metabolism of local ducks. J. Indon. Trop. Anim. Agric. 42:194-201. https://doi.org/10.14710/ jitaa.42.3.194-201

Baeza, E. 2006. Effects of genotype, age, and nutrition on intramuscular lipids and meat quality. In: L. Y. Ling, \& C. Sebastien (Eds). Scientific Cooperation in Agriculture. ROC, Tainan. p. 79 - 82.

Bolton, W. 1967. Poultry Nutrition. MAFF Bulletin No.174. HMSO, London.

BPS (Badan Pusat Statistik). 2018. Populasi Itik/Itik Manila Menurut Provinsi 2000-2018. https://www.bps.go.id/ dynamictable/2015/12/18/1036/populasi-itik-itik-manilamenurut-provinsi-2000-2018.html. [3 June 2018].

Burstein, M., H. R. Scholnick, \& R. Morfix. 1970. Rapid method for the isolation of lipoproteins from human serum by precipitation with polyanions. J. Lipid. Res. 11:583-595.

Cao, Z., B. Meng, R. Fan, M. Liu. M.Gao, Z. Xing, \& X. Luan. 2018. Comparative proteomic analysis of ovaries from Huoyan geese betweenpre-laying and laying periods using an iTRAQ-based approach. Poult. Sci. 97:2170-2182. http://dx.doi.org/10.3382/ps/pey029

Carvajal-Zarrabal, O., S. M. Waliszewski, D. M. BarradasDermitz, Z. Orta-Flores, P. M. Hayward-jones, C. 
Nolasco-Hipolito, O. Angulo-Guerrero, R. SanchezRicano, R. M. Infanzon, \& P. R. L. Trujillo. 2005. The consumption of Hibiscus sabdariffa dried calyx ethanolic extract reduced lipid profile in rats. Plant. Foods. Hum. Nutr. 60:153-159. https://doi.org/10.1007/s11130-005-9023-x

Choi, Y. S., J. H. Choi, D. J. Han, H. Y. Kim, M. A. Lee, J. Y. Jeong, H. J. Chung, \& C. Kim. 2010. Effects of replacing pork back fat with vegetable oils and rice bran fiber on the quality of reduced-fat frankfurters. Meat. Sci. 84:557-563. https://doi.org/10.1016/j.meatsci.2009.10.012

Fu, Z. F., Z. C. Tu, L. Zhang, H. Wang, Q. H. Wen, \& T. Huang. 2016. Antioxidant activities and polyphenols of sweet potato (Ipomoea batatas L.) leaves extracted with solvents of various polarities. Food. Biosci. 15:11-18. https://doi. org/10.1016/j.fbio.2016.04.004

Green, A. S. \& J. Fascetti. 2016. Meeting the vitamin A requirement: The efficacy and importance of -Carotene in animal species. Sci. World J. 2016: 1-22. https://doi. org/10.1155/2016/7393620

Hulu, D. P. C., S. H. Suseno, \& Uju. 2017. Improving the quality of sardine fish oil by degumming using sodium chloride solution. J. P. H. P. I. 20:199-210. https://doi.org/10.17844/ jphpi.v20i1.16508

Kuksis, A. 1992. Yolk lipids. Biochem. Biophys. Acta. 1124:205222. https://doi.org/10.1016/0005-2760(92)90132-F

Laudadio, V., E. Ceci, N. M. B. Lastella, M. Introna, \& V. Tufarelli. 2014. Low-fiber alfalfa (Medicago sativa L.) meal in the laying hen diet: Effects on productive traits and egg quality. Poult. Sci. 93:1868-1874. https://doi.org/10.3382/ ps.2013-03831

Leeson, S. \& J. D. Summers. 2005. Commercial Poultry Nutrition. 3rd ed. Nottingham Univ Pr, Nottingham.

Levi, L., I. Pekarski, E. Gutman, P. Fortina, T. Hyslop, J. Biran, B. L. Sivan, \& E. Lubzens. 2009. Revealing genes associated with vitellogenesis in the liver of zebrafish (Danio rerio) by transcriptome profiling. B. M. C. Genomics. 10:141-157. https://doi.org/10.1186/1471-2164-10-141

Liu, X., H. L. Zhao, S. Thiessen, J. D. House, \& P. J. H. Jones. 2010. Effect of plant sterol enriched diets on plasma and egg yolk cholesterol concentrations and cholesterol metabolism in laying hens. Poult. Sci. 89:270-275. https://doi. org/10.3382/ps.2009-00249

Maryuni, S. S. \& C. H. Wibowo. 2005. The effect of lysine and metabolizable energy levels in fermented cassava diet on feed consumption and body fat in broiler chicken. J. Indon. Trop. Anim. Agric. 30:26- 33.

McKee, T. \& J. R. McKee. 2013. Biochemistry the Molecular Basis of Life. 5th ed. Oxford Univ Pr, New York.

McNulty, H., R. F. Jacob, \& R. P. Mason. 2008. Biologic activity of carotenoids related to distinct membrane physicochemical interactions. Am. J. Cardiol. 101(10A):20D-29D. https:// doi.org/10.1016/j.amjcard.2008.02.004

Meng, Q., P. Long, J. Zhou, C. T. Hou, X. Zou, B. Chen, \& L. Zhang. 2019. Improved absorption of $\beta$-carotene by encapsulation in an oil-in-water nanoemulsion containing tea polyphenols in the aqueous phase. Food. Res. Int. 116:731736. https://doi.org/10.1016/j.foodres.2018.09.004.

Morgan, N. K. \& M. Choct. 2016. Cassava: Nutrient composition and nutritive value in poultry diets. Anim. Nutr. 2:253-261. https://doi.org/10.1016/j.aninu.2016.08.010
Rice-evans, C. A., A. T. Diplock, \& M. C. R. Symons. 1991. Techniques in Free Radical Research. Elsevier Sci., London.

Roeschlau, P., E. Bernt, \& W. Gruber. 1974. Enzymatic determination of total cholesterol in serum. Z. Klin. Chem. Klin. Biochem. 12:226-227.

Schettler, G. \& E. Nüssel. 1975. Cholesterol CHOP-PAP. Arb. Med. Loz. Med. Präv. Med. 10:25-35.

Schreiber, S. B., J. J. Bozell, D. G. Hayes, \& S. Zivanovic. 2013. Introduction of primary antioxidant activity to chitosan for application as a multifunctional food packaging material. Food. Hydrocolloid. 33:207-214. https://doi.org/10.1016/j. foodhyd.2013.03.006

Schweiger, M., T. O. Eichmann, U. Taschler, R. Zimmermann, R. Zechner, \& A. Lass. 2014. Measurement of lipolysis. Methods. Enzymol. 538:171-193. https://doi.org/10.1016/ B978-0-12-800280-3.00010-4

Scorletti, E., \& C. D. Byrne. 2013. Omega-3 fatty acids, hepatic lipid metabolism and nonalcoholic fatty liver disease. Annu. Rev. Nutr. 33:231-248. https://doi.org/10.1146/ annurev-nutr-071812-161230

Shahidi, F. \& Y. Zong. 2010. Lipid oxidation and improving the oxidative stability. Chem. Soc. Rev. 39:4067-4079. https:// doi.org/10.1039/b922183m

Shahidi, F. \& Y. Zhong. 2015. Measurement of antioxidant activity. J. Func. Foods. 18:757-781. https://doi.org/10.1016/j. iff.2015.01.047

Simons \& Sampaio. 2011. Membrane organization and lipid rafts. Cold Spring Harbor Laboratory Pr, Harbor. https:// doi.org/10.1101/pdb.prot4589

Steel, R. G. D. \& J. H. Torrie. 1980. Prinsiples and Procedures of Statistics. 2nd Ed. McGraw-Hill, New York.

Sumiati, A. Darmawan, \& K. G. Wiryawan. 2016. Egg quality and blood hematology of magelang laying duck fed with diets containing different ratios of omega 3 and omega 6 fatty acids and organic Zn. Int. J. Poult. Sci. 15:448-453. https://doi.org/10.3923/ijps.2016.448.453

Surai, P. F., I. F. Vladimir, \& K. Filiz. 2016. Antioxidant systems in chick embryo development. Part 1. Vitamin E, carotenoids and selenium. Anim. Nutr. 2:1-11. https://doi. org/10.1016/j.aninu.2016.01.001

Trujillo, L. S., \& E. A. Decker, \& D. J. McClements. 2016. Influence of an anionic polysaccharide on the physical and oxidative stability of omega-3 nanoemulsions: antioxidant effects of alginate. Food. Hydrocolloid. 52:690-698. https:// doi.org/10.1016/j.foodhyd.2015.07.035

USDA (United States Department of Agriculture). 2010. Dietary Guidelines for Americans. 7th Edition. United States Department of Agriculture Agricultural Research Service, Washington.

USDA (United States Department of Agriculture). 2018. USDA Branded Food Products Database. United States Department of Agriculture, Washington.

Watson, R. R. 2002. Eggs and Health Promotion. Iowa State Pr, New York https://doi.org/10.1002/9780470376973

Yu J., X. Bi, B. Yu, \& D. Chen. 2016. Isoflavones: anti-inflammatory benefit and possible caveats. Nutrients. 8:361-377. https://doi.org/10.3390/nu8060361

Zhenyi, A. \& A. W. William. 2016. Cholesterol: An Achilles' Heel for Glioblastoma. Cell Pr, California. 